\title{
Estimation of ferrioxamine and desferrioxamine in urine
}

\author{
J. FIELDING AND GILLIAN M. BRUNSTRÖM \\ From Paddington General Hospital, London
}

SYNOPSIS A method is described for the estimation of ferrioxamine and of desferrioxamine when either or both are present in urine.

Desferrioxamine is a trihydroxamic acid isolated from a strain of streptomyces (Bickel, von Gäumann, Keller-Schierlein, Prelog, Vischer, Wettstein, and Zähner, 1960), which belongs to the naturally occurring sideramines. It has highly specific chelating activity for trivalent iron, forming the ferric chelate, a red-brown compound, known as ferrioxamine.

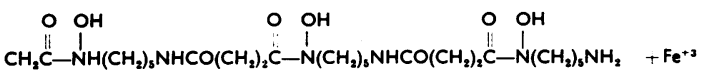

Desferrioxamine

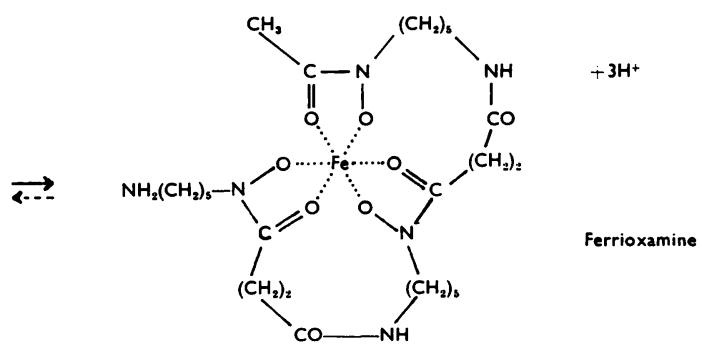

Chelating activity has been observed in vivo following intramuscular or intravenous injection of desferrioxamine, and the soluble ferrioxamine is excreted in the urine. The highly specific affinity for iron has suggested the use of desferrioxamine to increase iron excretion in haemochromatosis, in other forms of siderosis, and to bind ionic iron in the treatment of acute iron poisoning (Wöhler, 1962; Bannerman, Callender, and Williams, 1962; Smith, 1962).

The current method of estimating desferrioxamine (Keberle, 1962) estimates the total of desferrioxamine plus ferrioxamine. No clinical method is described for ferrioxamine alone, and the assessment

Received for publication 4 March 1964. of its excretion following injection of desferrioxamine is made by the direct estimation of iron in urine, a procedure which gives wide variations between laboratories (Keberle, 1963).

Korman (1960) suggested that sequestrene might be used to decolorize an iron chelate. A simple method, using such a reaction, is described here for the estimation of ferrioxamine and of desferrioxamine when either or both are present in urine.

\section{STABILITY OF FERRIOXAMINE WITH VARYING $p H$}

Ferrioxamine is highly stable at $p \mathrm{H} 6$ or more $\left(\mathrm{K}=10^{30}\right)$. The test procedure described below involves two reactions which proceed rapidly only at low $p \mathrm{H}: 1$ The decolorization of ferrioxamine with sodium sequestrene, and, 2 , the conversion of desferrioxamine to ferrioxamine with ferric chloride. The stability of colour for ferrioxamine at low $p \mathrm{H}$ was therefore investigated.

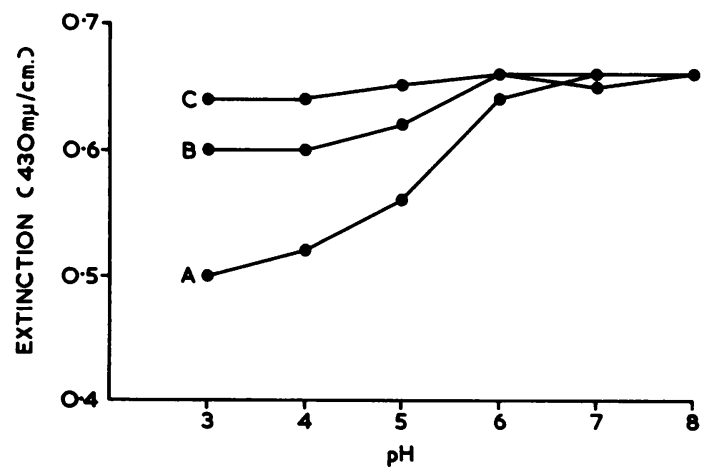

FIG. 1. Dissociation of ferrioxamine at low pH. A, $20 \mathrm{mg}$. per $100 \mathrm{ml}$. ferrioxamine in citric acid-phosphate buffers; $B$, plus $8 \mathrm{mg}$. per $100 \mathrm{ml}$. desferrioxamine; C, plus $24 \mathrm{mg}$. per $100 \mathrm{ml}$. desferrioxamine. 
A perceptible degree of dissociation and thus decolorization takes place below $p \mathrm{H}$ 6. This dissociation is prevented by the presence of excess desferrioxamine or by excess ferric chloride. Figure 1 shows the extinction at $430 \mathrm{~m} \mu$ of a solution of ferrioxamine in McIlvain's citric acid-phosphate buffers $p \mathrm{H} 3$ to $p \mathrm{H} 8$ with and without added desferrioxamine, showing the decolorization which takes place at low $p \mathrm{H}$. In a solution of ferrioxamine alone, significant decolorization takes place between $\mathrm{pH} 3$ and $p \mathrm{H} \mathrm{6}$, whereas in the presence of $24 \mathrm{mg}$. per $100 \mathrm{ml}$. desferrioxamine, extinction is constant between $p \mathrm{H} 3$ and $p \mathrm{H}$. The measurement of ferrioxamine extinction in the test to be described is therefore made in the presence of excess desferrioxamine. The minimum concentration of desferrioxamine required to give consistent results under the conditions of ferrioxamine estimation was empirically determined as $15 \mathrm{mg}$. per $100 \mathrm{ml}$. In the case of desferrioxamine estimation, the reagent ferric chloride serves both to convert to ferrioxamine and to stabilize ferrioxamine during the changes of $p \mathrm{H}$.

\section{METHOD FOR FERRIOXAMINE IN URINE}

PRINCIPLE The red-brown ferrioxamine is decolorized with excess sodium ethylenediamine tetracetic acid $\left(\mathrm{Na}_{2}\right.$ E.D.T.A.) which forms a colourless ferric salt. The reaction proceeds rapidly at $p \mathrm{H} \quad 2-4$ and more slowly at higher $p \mathrm{H}$. A citric acid-phosphate buffer system is used to lower the $p \mathrm{H}$ during the reaction and to restore $p \mathrm{H}$ before colorimetry.

REAGENTS All solutions are made in on-free water.

1 Standard ferrioxamine hydrochloride (Ciba) $50 \mathrm{mg}$. per $100 \mathrm{ml}$.

2 Standard desferrioxamine methanesulphonate (Desferal, Ciba) $40 \mathrm{mg}$. per $100 \mathrm{ml}$. (If desferrioxamine hydrochloride is being used, the same salt should be used to make the standard.) Both standard solutions should be accurately prepared from weighed samples.

3 Reagent desferrioxamine $0.5 \mathrm{~g}$. per $100 \mathrm{ml}$.

4 Citric acid, $\mathrm{H}_{3} \mathrm{C}_{6} \mathrm{H}_{5} \mathrm{O}_{7} \mathrm{H}_{2} \mathrm{O}$ (A.R.) 10.5 g. per $100 \mathrm{ml}$.

5 Disodium hydrogen phosphate $\left(\mathrm{Na}_{2} \mathrm{HPO}_{4} \cdot 2 \mathrm{H}_{2} \mathrm{O}\right)$ $19.8 \mathrm{~g}$. per $100 \mathrm{ml}$. This solution tends to supersaturate and precipitate at room temperature. It is redissolved by gentle heat and kept at $37^{\circ} \mathrm{C}$. before use.

6 Disodium ethylenediamine tetracetic acid Solid (B.D.H. reagent).

CALIBRATION OF STANDARD FERRIOXAMINE HYDROCHLORIDE Set up seven chemically clean test tubes and add the following volumes of standard ferrioxamine: $0,0.5,1.0$, $2 \cdot 0,3.0,0.5,3.0 \mathrm{ml}$. Make up to $5 \mathrm{ml}$. with ion-free water to give equal volumes of $0,5,10,20,30,5,30 \mathrm{mg}$. per $100 \mathrm{ml}$. ferrioxamine respectively. To each tube add $0.15 \mathrm{ml}$. reagent desferrioxamine $(0.5 \%)$ and follow with $0.4 \mathrm{ml}$. citric acid.
To the last two tubes add about $1.5 \mathrm{~g}$. solid sodium $\frac{\mathrm{m}}{\overrightarrow{7}}$ E.D.T.A., mix, and allow the tubes to stand for $10 \%$ minutes by which time decolorization should be com- $\vec{F}$ plete. (It may be found more convenient to have the $\stackrel{5}{?}$ E.D.T.A. in the tubes before the other reagents are added.) Then to all tubes add $1.5 \mathrm{ml}$. disodium hydrogen $\overline{ }$ phosphate, and, after mixing, tubes 6 and 7 are lightly $\frac{\bar{m}}{7}$ centrifuged. Measure extinctions in a suitable spectro- $\mathbb{D}$ photometer at $430 \mathrm{~m} \mu$ setting tube 6 to zero. Tube $7 \stackrel{\circ}{\mathrm{d}}$ should give zero reading; if not, an inadequate amount $\omega$ of E.D.T.A. has been used and decolorization is in- $\overrightarrow{0}$ complete.

When extinction is plotted arithmetically against the $\vec{\omega}$ concentration of ferrioxamine in the $5 \mathrm{ml}$. volumes? tested, a straight line through the origin is obtained. 8 The same graph is obtained when standard ferrioxamine dilutions are prepared in urine; 25 different urines have given the same result when tested in this way.

FERRIOXAMINE IN URINE Two chemically clean test tubeso are required. Measure into each $5 \mathrm{ml}$. of test urine. Add $0.15 \mathrm{ml}$. reagent desferrioxamine $(0.5 \%)$, mix, and follow with $0.4 \mathrm{ml}$. citric acid. To the second tube add $1.5 \mathrm{~g}$. $\mathrm{Na}_{2}$ E.D.T.A., stand for 10 minutes, then to both $\overrightarrow{\vec{C}}$ tubes add $1.5 \mathrm{ml}$. $\mathrm{Na}_{2} \mathrm{HPO}_{4} .2 \mathrm{H}_{2} \mathrm{O}$ reagent. All specimens $\%$ are centrifuged at 3,000 r.p.m. for 10 minutes or until $\uparrow$ the supernatants are water clear.

The spectrophotometer is set to zero with tube 2 and the extinction of tube 1 is read directly from the standard calibration curve as a concentration of ferrioxamine in the test urine. Should the ferrioxamine concentration be $\frac{0}{\mathbb{D}}$ above the calibration range, the urine is suitably diluted $\cong$ with water and the test repeated.

\section{METHOD FOR DESFERRIOXAMINE AND FERRIOXAMINE IN URINE}

PRINCIPLE Ferrioxamine is estimated as described: above. In a second aliquot the colourless desferrioxamine 3 is converted to ferrioxamine with ferric chloride and $a_{\text {c }}$ control obtained by decolorization with sequestrene. $\frac{3}{3}$ By difference the colour intensity due to desferrioxamine alone is obtained and read from a standard graph. 9 Ferric chloride also reacts with small quantities of normal urinary constituents to give coloured products which are also decolorized by sequestrene salts at low $p \mathrm{H}$. This minor reaction requires consideration in arranging aO suitable blank.

REAGENTS In addition to the reagents given above:

7 Ferric Chloride $\mathrm{FeCl}_{3} .6 \mathrm{H}_{2} \mathrm{O}\left(\mathrm{A} . \mathrm{R}\right.$.) $1.5 \mathrm{~g}$. per $100^{\circ}$ $\mathrm{ml}$. in ion-free water.

CALIBRATION OF DESFERRIOXAMINE STANDARD Into eight test tubes add aliquots of standard desferrioxamine methanesulphonate $(2 \%)$ as follows: $0,0 \cdot 5,1 \cdot 0,2 \cdot 0,3 \cdot 0 \frac{\mathrm{P}}{\mathrm{D}}$ $4 \cdot 0,0 \cdot 5,4.0 \mathrm{ml}$. and make up to $5 \mathrm{ml}$. with ion-free water? to give equal volumes of $0,4,8,16,24,32,4,32 \mathrm{mg}$. peß르 $100 \mathrm{ml}$. respectively.

To each add $0.4 \mathrm{ml}$. citric acid reagent, followed by $0.15 \mathrm{ml}$. ferric chloride and allow colour to develop foon 


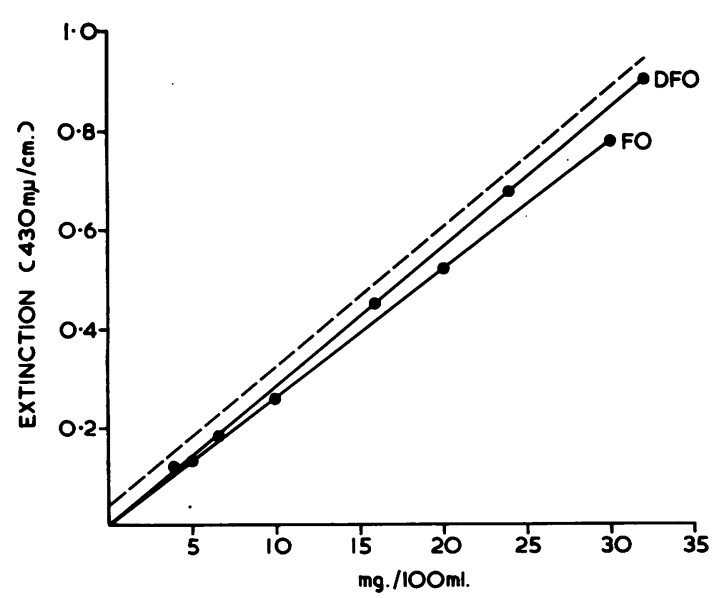

FIG. 2. $F O=$ calibration graph for standard ferrioxamine hydrochloride; $D F O=$ calibration graph for standard desferrioxamine methanesulphonate. The difference in slope agrees with that required by the molecular weights. The dotted line shows the graph obtained when desferrioxamine is made up in urine (see text on desferrioxamine blank).

10 minutes. Subsequent procedure is as for ferrioxamine calibration: to tubes 7 and 8 add $1.5 \mathrm{~g}$. solid $\mathrm{Na}_{2}$ E.D.T.A. and after decolorization, to all tubes add $1.5 \mathrm{ml}$. disodium hydrogen phosphate. Tubes 7 and 8 are lightly centrifuged. Extinction of each solution is read against tube 7 as zero. Again tube 8 acts as an indicator of complete decolorization. The graph of extinction against desferrioxamine concentration is a straight line through the origin (Fig. 2).

When standard desferrioxamine is made up in normal urine and the aliquots made up to $5 \mathrm{ml}$. with the same urine, the resulting curve is also a straight line which does not, however, pass through the origin, but is parallel with the graph produced in distilled water (Fig. 2). This displacement of the origin results from the minor reaction of ferric chloride with normal urinary constituents referred to above. A correction is therefore required when estimating desferrioxamine in urine, which is considered below.

DESFERRIOXAMINE AND FERRIOXAMINE IN URINE A pre- test specimen of urine is obtained from the patient for use as a desferrioxamine blank. It is treated in the same way as the test urine for desferrioxamine estimation (Table, tubes 5 and 6). Tube 5 is read against tube 6 as zero and represents the reaction of normal urinary constituents. Its extinction is therefore subtracted from subsequent desferrioxamine values.

The test urines are collected in chemically clean containers. For each test urine, four tubes are set up. The procedure followed is summarized in the Table. All tubes are finally centrifuged at 3,000 r.p.m. for five to 10 minutes.

Read the extinction of tube 1 supernatant at $430 \mathrm{~m} \mu$, setting tube 2 to zero, and convert to ferrioxamine concentration directly from the standard terrioxamine graph, as described above. Read the extinction of tube 3 setting tube 4 to zero. The reading of tube 3 is corrected by subtraction of the desferrioxamine blank (tube 5). The corrected reading represents the combined value for desferrioxamine converted into ferrioxamine, plus the ferrioxamine originally present. From the corrected value, therefore, subtract the extinction of tube 1 to obtain the reading due to urinary desferrioxamine alone, from which its concentration in milligrams per $100 \mathrm{ml}$. is read from the standard desferrioxamine graph.

A SOURCE OF ERROR There is a small potential error in the method for desferrioxamine since the blank urine is not the same specimen as the test urine: the content of ferric-chloride-reacting substances (other than desferrioxamine) may be different in the two specimens. A comparison of morning and afternoon specimens obtained on the same day from each of 25 patients showed that the mean difference between extinction readings (read at $430 \mathrm{~m} \mu, 1 \mathrm{~cm}$. cell) of the two specimens, when treated as described for the desferrioxamine blank, amounted to 0.011 with a standard deviation of 0.007 , corresponding to a difference of approximately 0.2 $\pm 0.1 \mathrm{mg}$. per $100 \mathrm{ml}$. desferrioxamine. This is small compared with the errors inherent in the collection of urine specimens and may be disregarded.

A more serious source of error arises when the patient is excreting drugs which give coloured compounds with ferric chloride e.g., salicylates, P.A.S., isoniazid, oxytetracycline, chlorpromazine, and the estimation cannot be done accurately in these circumstances. Urinary blanks which give extinction values greater than 0.07 $(430 \mathrm{~m} \mu 1 \mathrm{~cm}$.) should be suspect. These potential sources

TABLE

\begin{tabular}{|c|c|c|c|c|c|c|}
\hline \multirow[b]{2}{*}{ Tube Number } & \multicolumn{2}{|c|}{ Ferrioxamine Test } & \multicolumn{2}{|c|}{ Desferrioxamine Test } & \multicolumn{2}{|c|}{ Desferrioxamine Blank } \\
\hline & 1 & 2 & 3 & 4 & $\mathbf{5}$ & 6 \\
\hline Test urine (ml.) & $5 \cdot 0$ & $5 \cdot 0$ & $5 \cdot 0$ & $5 \cdot 0$ & - & - \\
\hline Pre-test urine (ml.) & - & - & - & - & $5 \cdot 0$ & $5 \cdot 0$ \\
\hline Reagent desferrioxamine (ml.) & $0 \cdot 15$ & $0 \cdot 15$ & - & - & - & - \\
\hline Citric acid (ml.) & 0.4 & 0.4 & 0.4 & 0.4 & 0.4 & 0.4 \\
\hline Ferric chloride (ml.) & - & - & $\begin{array}{c}0.15 \\
\text { minutes }\end{array}$ & $0 \cdot 15$ & $0 \cdot 15$ & $0 \cdot 15$ \\
\hline $\mathrm{Na}_{2}$ E.D.T.A. (g.) & - & $1 \cdot 5$ & minutes & 1.5 & - & $1 \cdot 5$ \\
\hline $\mathrm{Na}_{2} \mathrm{HPO}_{4}(\mathrm{ml})$ & $1 \cdot 5$ & $1 \cdot 5$ & $1 \cdot 5$ & $1 \cdot 5$ & $1 \cdot 5$ & $1 \cdot 5$ \\
\hline
\end{tabular}


of error apply only to desferrioxamine estimation. Ferrioxamine estimation is unaffected by the naturally occurring substances or drugs which react with ferric chloride.

We wish to thank Ciba Ltd. for gifts of ferrioxamine and desferrioxamine, and the Clinical Research Committee, North West Metropolitan Regional Hospital Board, for a grant.
REFERENCES

Bannerman, R. M., Callender, Sheila T., and Williams, D. L. (1962) Brit. med. J., 2, 1573.

Bickel, H., von Gäumann, E., Keller-Schierlein, W., Prelog, V. Vischer, E., Wettstein, A., and Zähner, H. (1960). Experientiðo (Basel), 16, 129.

Keberle, H. (1962). Ciba information.

- (1963). Ibid.

Korman, S. (1960). Ann. N.Y. Acad. Sci., 88, 460.

Smith, R. S. (1962). Brit. med. J., 2, 1577.

Wöhler, F. (1962). Schweiz. med. Wschr., 92, 1295. 